\title{
Risk and Financial Management Practice in the Construction Sector in Nigeria, System Thinking Perspective
}

\author{
Samuel Ekung \\ School of Built Environment, University of Salford, Greater Manchester, United Kingdom \\ E-mail: sambassey76@yahoo.com
}

\begin{abstract}
Risk and financial management of construction projects have been widely studied using different approaches and systems. Three basic frontiers underpin project management research in this area: normative; descriptive; and instrumental. The descriptive approach deals with how project managers perceive and represent risks that is, risk analysis. Instrumental approach study's the impact of risk management on projects and the organisation. This perspective informs the premise in which studies that seek to justify the need for risk management are based. The normative approach identifies the moral and ethical linkages between the individual, organisations and supra system and risk management practice. While a vast of number of studies have been descriptive and instrumental, very few however address systemic issues impacting risk and financial management practice. This paper sets out to reflect on the risk and financial management practice in Nigeria using system approaches. It is a critical appraisal involving SLEEPT, Multiple goal and the GESTALT theories. In reprising the problem, the report assessed the national economy of Nigeria using SLEEPT, with a view to establishing whether it is situated in extremistan or mediocristan. The organisation, a sub-system of the supra system is evaluated to establish its links with the supra system using GESTALT. A refinement is carried out based on these analyses in order to achieve congruence and to establish a baseline upon which risk and financial can be improved. The analysis reveals social, political, environmental and economic context of the supra system are in extremistan while the legal and technology are in mediocristan. The linkage in the different systems is anchored on decision making by the individual. Optimal decision making is therefore formulated using interactive framework.
\end{abstract}

Keywords: extremistan; decision-making; financial management; Nigeria; mediocristan; risk management; system theories

\section{INTRODUCTION}

Construction involves risk based processes that can be improved if the risks are identified and managed appropriately. In managing threat to projects, appropriate decision making strategy is often devised based on the organisation's objectives. Effective decision making on the other hand involves matching relevant strategy with states of nature and outcome. States of nature refers to uncertainties or risk beyond project organisations' control. Closely related to the states of nature assumption is the need to manage the safety of the budget of investment and to make effective decision-making when financial risks occurs (Brigham \& Houston, 2013). Financial risk management involve the management of risk associated with liquidity, interest 
rate, exchange rate, inflation, credit, refinancing where public sector is involve, legal and regulatory, market features (Eaton, 2013), and misappropriation. This is the basis within which the subject of the report is contextualised.

\section{MEDIOCRISTAN OR EXTREMISTAN}

The terms are two popular contemporary thinking that have shaped the world of financial risk management. According to the proponent, the world thinking that regulates financial management is predicated on probabilities based on past experience. But recent experience mainly the 2007/2008 economic recession has prompted a rethink based on the fact that, there exist 'black swans' with negligible probabilities, representing completely a new phenomenon that can impact or create disorder in a system.

Mediocristan explains the state of nature in which anticipated events happen, future are fairly predicted with definite probabilities such that if deviations occur, the impact is simply insignificant. Mediocristan is simply the easy to predict, the expected high probability impact state of nature. Events in mediocristan are constrained by boundaries of diverse conditions such as time, macroeconomic policies and professional practice. Normal distribution (Figure 1) where things are fairly predicted is a flag of mediocristan. Increasingly, the cash flow; returns; labour productivity and even variants to these variables are assumed to be normal in every construction project.

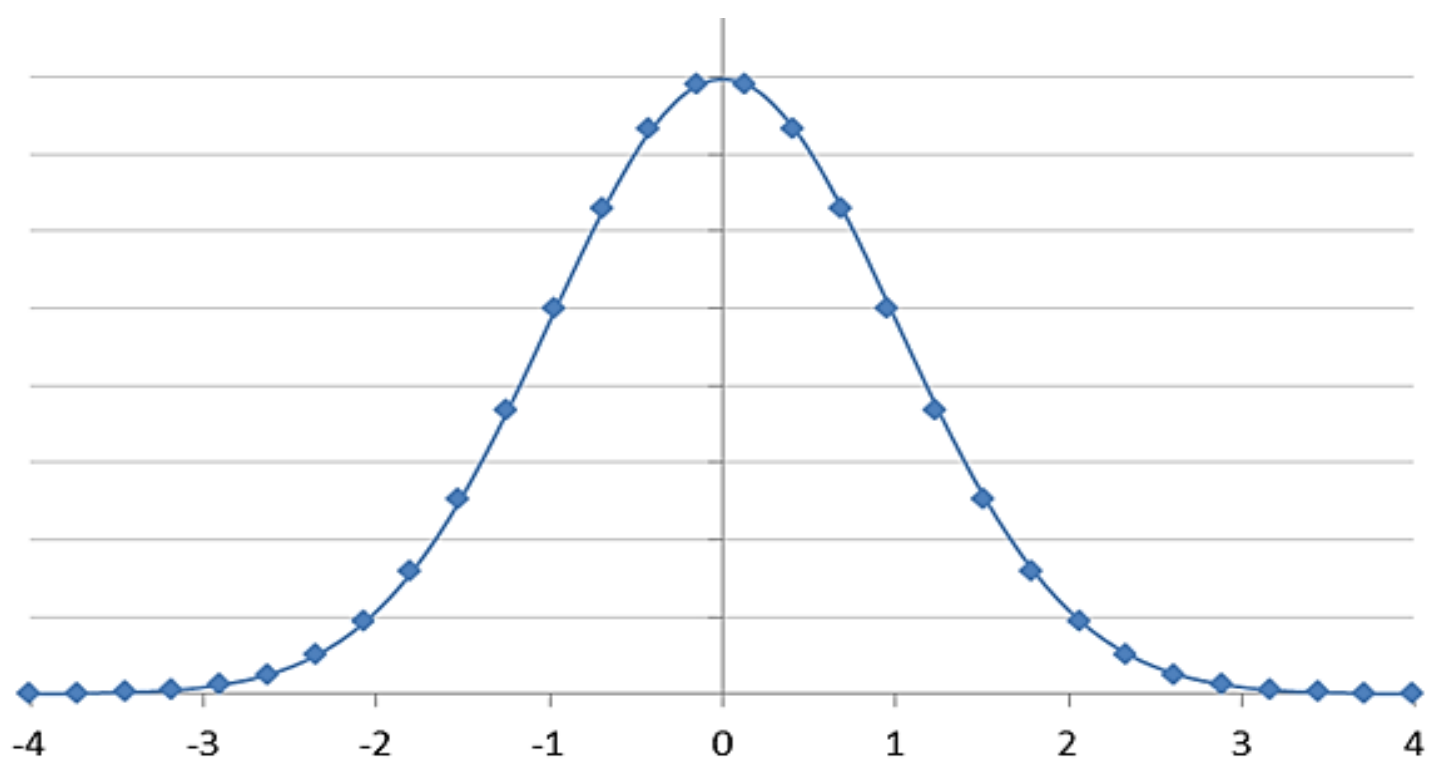

Figure 1. Normal Distribution as a Symbol of Mediocristan.

Black Swan events are situated in extremistan; in which case, the probability with which predictions are made is very small but with a titanic impact. They are rare and the probability of their occurrence is very small. The probability of earthquake happening in Nigeria is $0.000 \ldots$ since there is no past experience. 


\begin{abstract}
Extremistan ... instance, wealth, poverty, income, populations of cities; damage caused by disaster such as earthquake, flood, and drought, economic data, and almost all social events ...
\end{abstract}

(Taleb, 2010: 63).

\title{
2. 1. Risk and Financial Management and Extremistan or Mediocristan: The Relevance
}

Construction project risk management is largely regulated by the contractual form adopted. This is a predictable practice which can be conveniently placed in mediocristan. Financial management on the other hand is positioned in extremistan. Market forces relating to credit, exchange rate, liquidity etc. cannot be predicted with precision. Acknowledging the existence of black swans will drive a new culture towards improve risks and financial management?

Also emphasizing the existence of black swans will demystifies erroneously generated expectation often held undetermined in almost every construction project. It could help the sector to reconsider existing approaches towards project implementation by prioritizing only necessary things for improve performance. It will drive the need to diversify and internalized existing practices. Diversification is seen as the most effective strategy for surviving the effect of improbable rare events (Taleb, 2010).

There is no diversification that is risk free. Such word as 'medium-risk' are mere catch phrase since risk assessment can't be adjudged holistic at a particular time in a project life cycle. There is no such enclave as holistic risk register for any project and development. Global impetus must shift from medium-risk seeking and risk free to very risky venture and this is the hallmark of diversification.

\section{SYSTEMS ANALYSES}

\section{1. The Individual and Multiple Objective Theories}

Most decision makers in the construction sector begin a career as trainee. In the context of this study, the quantity surveyor as a decision maker is considered. Every trainee is faced with the pressure of attaining proficiency in the job to achieve growth in the organisation's hierarchy while contributing to the attainment of its corporate objectives. The multiple objectives structure in this context reflects multiple goal concepts in system theory. Unfortunately, the individual's objective tend to be in tandem with the corporate organisational goal but since economic benefits drives mainly the individual's goal; incompatibility is thus established in boundary friction with the main organisational sub system driven by profit making.

Since every beginner is expected to start small, a trainee's personal beliefs are therefore subjugated in mediocrity. According to Weiner (2008), "mediocristan is dominated by belief in mediocrity". But since we live in the world of extremistan (Taleb, 2010), motivated by the ambition to be great someday, extreme events thus matter to everyone.

\section{2. The SLEEPT Analysis of Nigeria's Supra System}

The SLEEPT technique describes the different pattern of risks in a given system. It does not only analyse the different mechanics of risks in a system but also define the behavioural pattern of inherent risk in any system. Figure 2 depicts the overall performance of the Nigeria 
economy based on 2012 Global Competitiveness Index. Twelve pillars are used to assess the performance of each country as indicated in the outer sphere. The inner cores blue and sky-blue are the comfort zones and Nigeria is doing quite very well in its macroeconomic policies hence their position in the zone. Market size, labour efficiency and financial market are largely undeveloped areas waiting to be explored.

Political: Nigeria returns to democracy in 1999. Since then, she has been making transition from one civilian rule to another. These transitions are not without hitches; election results are still contested up to the apex court in the country. The "nascent" democracy is seriously threatened by complacent security challenges. Militant insurgency up north is posing a deep threat to the geographical entity called Nigeria. Security and policy instability is a nonpredictable event situated in extremistan. It poses imminent danger to life and property. Several scores of persons have been killed and this is a significant impact. It also threatened the investment climate amidst financial management capability of the national economy. Based on these impetuses, the political context of the Nigeria's supra system is in extremistan.

Economical: Nigeria's growth is acknowledged to be robust, with over $40 \%$ in GDP (CSP, 2012). It is driven mainly by crude oil and a small proportion in agriculture while the oil and gas remain the main stay of the economy in terms of foreign direct investment and foreign exchange. Fiscal management is based on the Fiscal Responsibility Act 2009. The fiscal deficit is set within 3\% of GDP since 2010 with medium term strategy aimed at restructuring fiscal float, minimizing spending in recurrent items to boost capital expenditure. Monetary policy since 2011 is targeted at single digit inflation and has tightened fiscal consolidation with comprehensive check on inflation.

The rate in economic growth has declined significantly in $2012-6.2 \%$ and $6.3 \%$ compared to $7.7 \%$ in the last quarter of 2011(NBS, 2012). Robust fiscal strategy is in place for the medium and long term; this perhaps informs the improved rating in the world global competitiveness rating. However, Nigeria is at low risk in debt distress according to DSA (2012) but concerns arise as a result of increasing debt profile of the nation. The rising debt profile of Nigeria poses imminent danger to the financial sector. Two factors are notably responsible for the rising debt profile of Nigeria (CSP, 2012): poor governance and fiscal federalism. According to Taleb, economic data and variables are highly improbable and non-scalable and are therefore situated in extremistan. Based on this premise, the economic variable is in extremistan.

Technological: Nigeria growth rate in this sector is low based on the last Global Competitiveness ranking. Actors believe the country is not ready to improve technologically as evidenced in its low ICT penetration. Experts attribute this to poor educational system. However capacities are being developed through scholarship abroad and revitalization by private sector intervention in training, equipping and the provision of physical infrastructure. This is a state of mediocristan. 


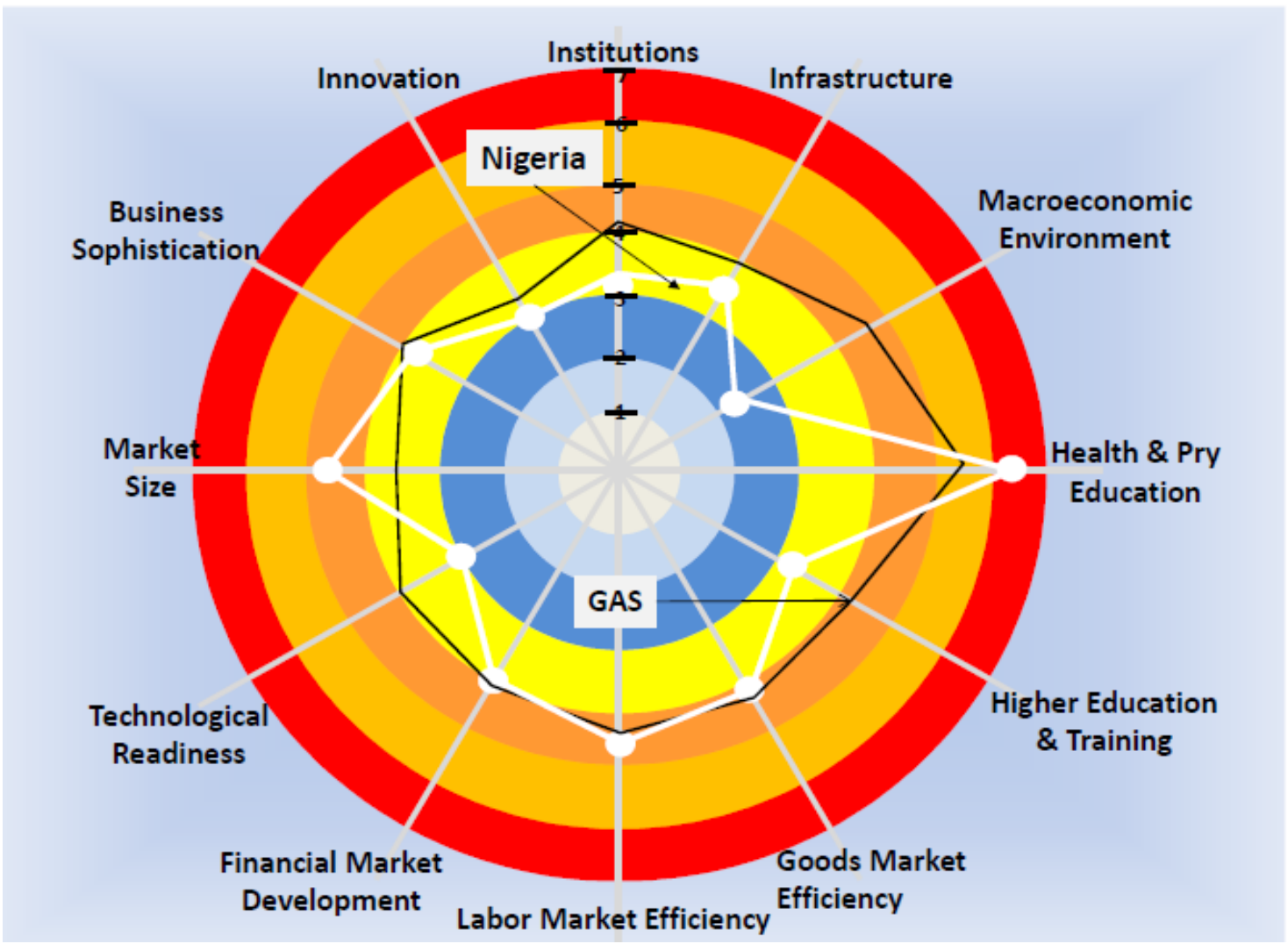

Figure 2. Overview of the Performance of Nigerian Supra System (Micaiah, 2012).

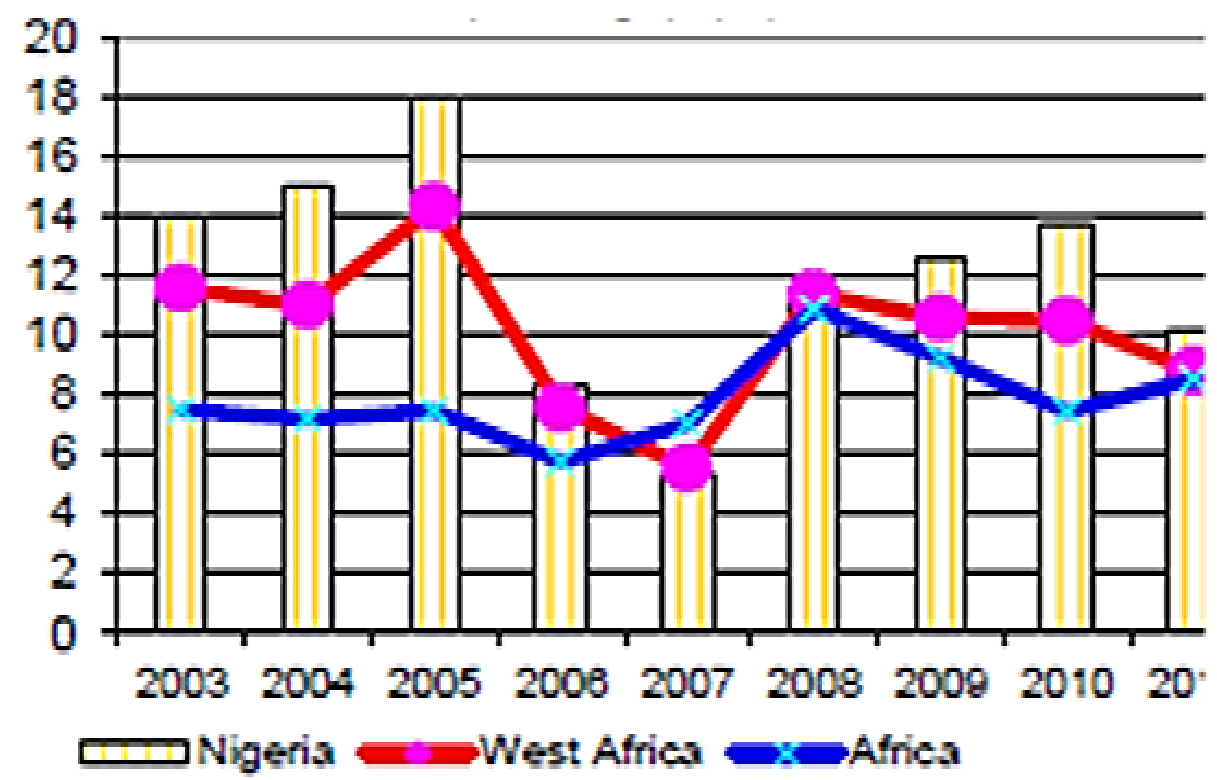

Figure 3. Sectoral Contribution to GDP \& Consumer Price Index of Nigeria (CSP, 2012). 
In the social context, the economy is in deep state of social deprivation. About $63 \%$ of the populace lives below poverty line of $\$ 1$ per day. $42 \%$ have no access to safe drinking water while $69 \%$ has no access to sanitation (CSP, 2012). Unemployment is steadily on the rise, although with advance progress in achieving Millennium Developments Goals (MDGs). Efficient gender policies are not translated into implementation to guarantee empowerment and equality. Therefore, since social events are extreme extremistan indicators; and whereas Nigeria has not improved on these indicators, it is in a state of extremistan.

Environmental, the economy depends heavily on climate sensitive sector/activities. Agriculture employs about $70 \%$ of the total workforce. Threat of natural disaster is on the increase notably flood, desert encroachment and drought which have impacted significantly on food security, water and air quality and pollution. Gas flaring and pollution from oil exploration have devastated the economy of the Niger Deltans. The Nigerian environment, notably the Niger Delta is highly vulnerable to climate change. Again, environmental factors are highly improbable and non-scalable; therefore Nigeria is in a state of extremistan

On the legal perspective, there has been significant improvement in the institution of government notably in the judiciary and legislature. It is based on English Law system but legal context goes beyond the law; it addresses excessive bureaucracy, overregulation, corruption, dishonesty in administering public contracts and the lack of transparency. Others are appropriate service for the business sector, political dependence of the different arms of government and proper management of public finances. There is a significant improvement on the independence of the judiciary, non-biasness of the judges and sanctioning of erring officials. There is also increase awareness on the part of the citizenry as demonstrated by recent protest that greeted the mild sentence granted to Pension Fund's thief who admits being guilty in court. The reaction by the populace led to re-arrest and further trial. Recently also, three erring judges were dismissed from service due to connivance allegations established against them in cases involving former office holders notably governors. From this premise therefore, the legal context is predictable and is in the state of mediocristan.

This is the macro outlook of the Nigeria supra system in perspective. Vast untapped market remains the most attractive indicator for investors but the flow in foreign direct investment does not correlate this improvement. Analyst attribute this to the lack of framework to appropriately assessed and mitigate risks on the part of the proponents stand out unscathed. Imperatives for improvement should aim at attaining midpoint between mediocristan and extremistan.

\section{3. Impact of Supra System Context on the Construction Sector}

The development of the construction sector is tied to the development of infrastructure. Inherent risk in the macro environment impacts on the delivery of efficient infrastructure thus exposing the country to wide infrastructure deficiency gap. The trend leads to the shortage of technical expertise, rigid regulatory policy, financing difficulty and misappropriation and poor policy implementation (Oluwakiyesi, 2011). As a result, the construction industry in Nigeria operates a two tier structure: advanced and sophisticated sector of the foreign multinationals and the labour intensive local sector. Due to over dependent on foreign expatriates, the local participants are inexperienced and unskilled. From deal structuring perspective, experts in the financial institutions do not have the expertise to structure infrastructure projects in broad project financing option.

Rigid policy regularization on the other hand has shut the door against other interested new entrant into the market. For instance, based on World Bank account on ease of doing 
business, Nigeria ranks $167^{\text {th }}$ out of 183 countries with 350 days compared to other sub-Saharan countries like Tunisia with (Figure 4 ) just 84 days.

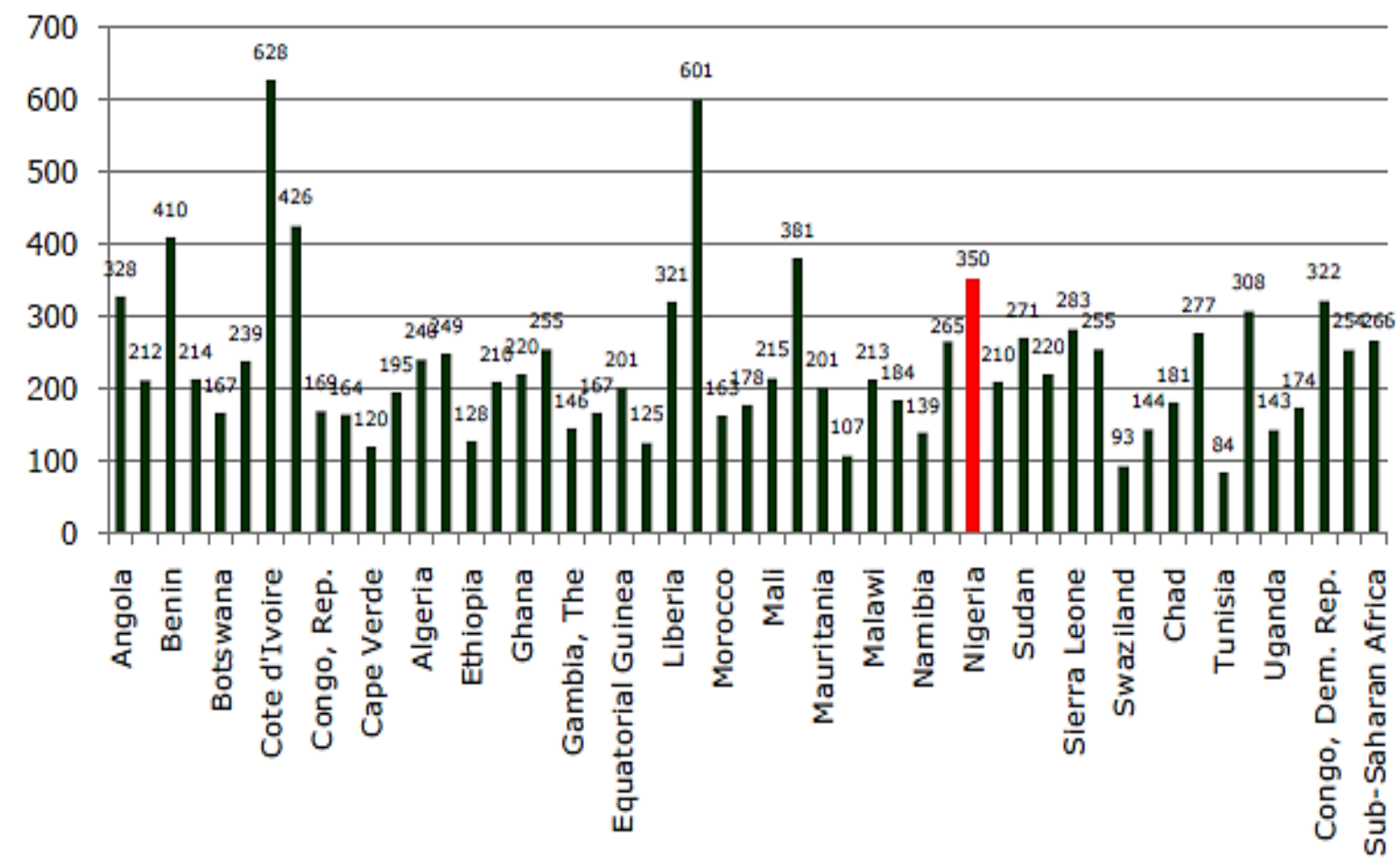

Figure 4. Dealing with Construction permit (days) (WB Database, Vetiva Research).

\section{THE ORGANISATION}

A public liability coy enlisted in the Nigerian Stock Exchange since 1991 is appraised. The company remains the market leader in the Nigerian construction sector, executing jobs in the region of $60 \%$ of the total Federal government contract in various sub-sector of construction (Oluwakiyesi, 2011). However, it does not exist as a monopoly but has to survive stiff competition from the highly subsidised Chinese Construction Company among other medium sized contracting organisations in recent years.

As a sub-system of the supra environmental system, it interacts with the industry, its key player and stakeholders to provide a satisfactory service (Eaton, 2013). This includes the clients (Federal States and Corporate Private Sector); construction professionals, legal associations and their professional bodies. Although a greater proportion of its workforce notably at middle level cadre are largely expatriates. It operate an open system thereby encouraging information interchange with the supra system within which it operates.

The organisation philosophy is aligned to GESTALT and differentiation system concepts. According to Gould \& Kolb in Eaton (2013), the GESTALT describes:

" an entity ..., though distinguishable, is interdependent; the whole has certain characteristic belonging to none of the parts and parts have certain..." 
As a GESTALT organisation, the organisation engage in a number of specialised functions in building (offices, functional buildings, residential, sports/recreation etc.); infrastructure (roads, bridges, railway, airport and social amenities), industrial construction (plants and factories, oil and gas and power stations) and marine (ports, jetties and dredging).

The company was established as a subsidiary of a German based construction firm contracted to work on a bridge building project in 1965. But today, it has drawn from import and resources in the supra system to create unique sub-sub-system (building, industrial and marine constructions).

As a differentiated company, there is division of task aligned in each sub-sub system with unique feature that tend to create subdivision in the system. Such special unit includes foundation technology unit; technical services (design and engineering, budget estimates and project management), offsite construction units and manufacturing where steels and aluminium products are produced.

From the foregoing analysis, it is obvious that the organisation is operated on a set of predictable rules. Markets are forecasted, analysed and predicted using the properties of the normal distribution curve. Being the market leader, bids outcome can be fairly predicted with very high probability like every other event in the Taleb's mediocristan. The system dynamics of the organisation is therefore in mediocristan. Conversely, the organisation is capitalised in the stock exchange which is a member of the financial sector which Taleb situates in extremistan.

\section{DEFINING SYSTEM CONGRUENCE}

From individual perspective to the organisation and the supra system, a central theme is conflicting needs and objectives that drives our expectation from another. According to Eaton (2013), 'the concept of system congruence is that of matching needs by reducing system conflict and frictions". Every system has a set of conflicting objectives to meet, the supra system needs the infrastructure to attain economic development, the organisation has profiteering need and the individuals has personal growth and improvement needs. According to Dale Carnegie, the best way to satisfy one's goal is to satisfy the need of others. The supra system is at the cross road (Tosin, 2012), the organization is better placed to assist both the individual and the supra system. Michael Porter's Diamond Model (Figure 6) represents a congruence resolution platform for the system conflicts in this context. Porter postulates that 'sustained growth has hardly ever been built on basic inherited factors such as land, location, natural resources, labour and population' '(1991:3).

Unfortunately, these are the mechanics upon which the Nigerian supra system is built. According to Porter (1991), competitive advantage is a product of interlinked advanced activities in and between companies' clusters namely: 'firm strategy, structure and rivalry; demand conditions, related supporting industries and factor condition'.' The world is governed by dynamic factors and this implies competition will prompt increase productivity and innovation. The supra system needs to step up demand from the firm for innovative products that represent a complete departure from existing practice while developing supporting industries to enhance information exchange. The supra system can stimulate stiffer competition from other players such as China Construction Company to be able to draw on their finances and economic of scale which they can also offer. There is need to also diversify the economy from oil not just as a mean of surviving in the improbable prone supra system but to also improve risk and financial management. 


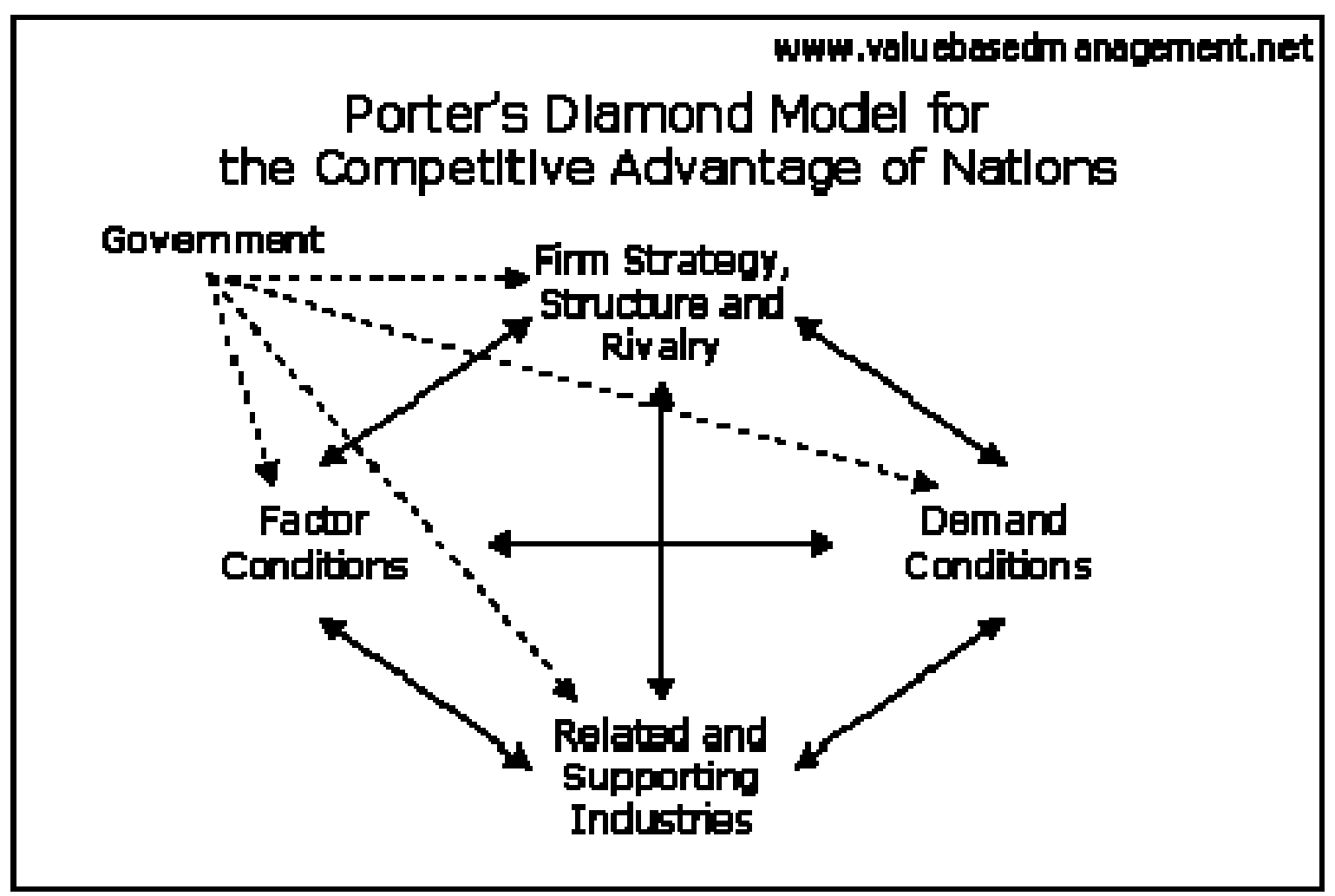

Figure 6. Porters Diamond Model for Competitive Advantage of Nations (Porter, 1991).

The main cause of the supra system's failure is weak institutional framework, low economic development, poverty, misappropriation, and lack of development funds. Efficient infrastructure underpinned sustained economic development. The organisation is heavily capitalized and is capable of generating any amount in the stock exchange to fund infrastructure projects. The organization should consider infrastructure provision through PFI. In so doing, the supra system will be constrained to budgeting for unitary payments and misappropriation will be minimized. PFI enhance improved decision making based on rational criteria and habours improved risk and financial management. The organization will further push its frontiers beyond competitive reach and sustained its market leadership and strengthened its survival in the black swan ridden supra system.

\section{THE LINKAGES}

The link between the individual, organisation and the environmental supra system is indeed interwoven. Key word to establishing how the trio affect one another in respect to risk and financial management is decision making. In this context, the individual is a quantity surveyor at the decision making level. Based on his inputs, markets are analysed and demand forecasted. Contract decisions are made in competition with other firms. The strength of such decision and the basis in which they are taken determines if the organisation get the contracts and what profit is made. Key to such decision is risk assessment and financial appraisal. On the other hand, the public sector finance and pay for the services of the organisation. They 
determine the demand and which organisation gets the work based on decisions presented by the competing organisations. The satisfaction of all parties in the chain therefore is strongly dependent on the decision fed into and made by the systems.

The construction industry decision making is largely based on qualitative parameters which has proved detrimental to the overall project objectives. To help all parties in solving the problems that might constraint decision making about risk exposure and financial management, the public sector must outstepped the boundaries of rules regularization in disclosing relevant information more than required to help strengthen decision making by the private sector.

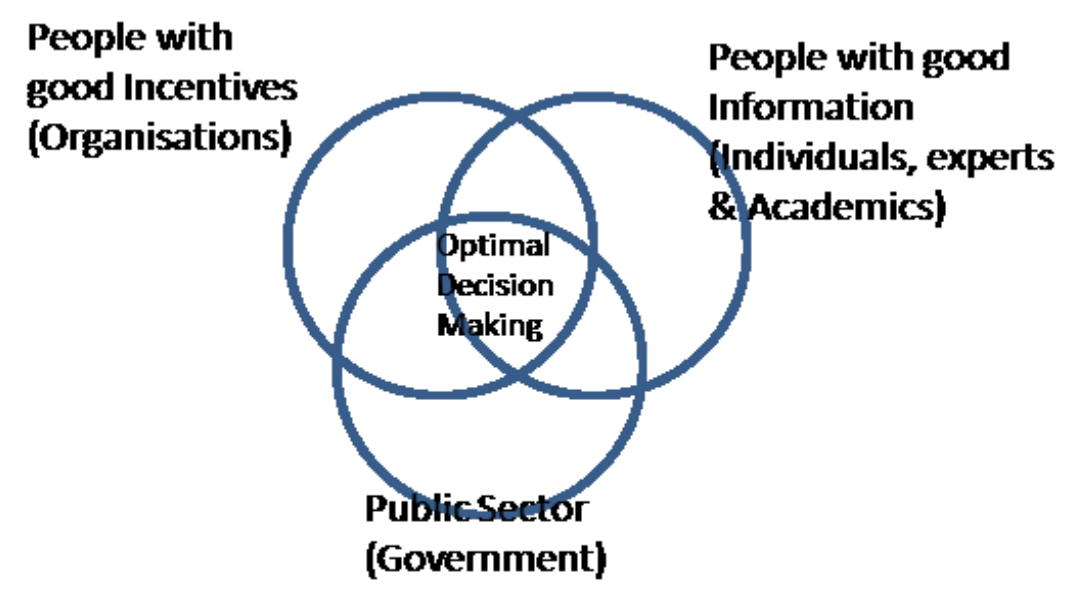

\section{Framework for Improved Decision Making}

Figure 7. Decision Making Framework.

Policy risk is the key threat to all parties in the supra system. Policy risk is the unpredictable discrepancy in value creation arising from unpredictable changes in government action. From the framework above, two approaches to improving decision making eschewed: first, conceding the right to make decisions to someone better equipped to make them; and second, improving incentives and information of the inherent decision makers in the system. The goal is to place this set of decision makers at the intersection in Fig. 7. The intersection represents people with improved information and good incentives. A good incentive scheme may consist of making policies that will create information and make them public for easy accessibility. However, Good decision also requires good advice; the capability of the decision maker need be assessed and improved in terms of information usage.

\section{CONCLUSIONS}

To improve decision process in a conflicting system, there is need to explore refinements to every risk exposure decision by seeking additional information (Bayesian Theory). This is necessary because at this level, the state of nature lies completely in extremistan. Seeking information to improve decision making requires the provision of adequate incentive to the individuals and supra government must make available the required information. Further refinement could be obtained by using pay-off matrix. As captured in Prospect Theory, the 
carriers of utilities are not states of the world, but gains and losses in relation to a reference point. The reference point must be clearly defined and it is the melting pot of optimal decision making in the framework above. Other quantitative risk assessment technique such as MERA (multiple estimation risk analysis) could be helpful even in the public sector. Therefore, the organisation must match appropriate decision strategy with state of nature analysis. The possible outcome might see the organisation competing with other large firms in the tensely conflicted supra system. The organisation should consider Decision Making Under Risk, Competition or Conflict (DMURCC). DMURCC because a plethora of relevant information would yet be unknown thereby making them largely uncertain; based on incomplete set of knowledge, strong possibility of limited knowledge of requirements and above all unstable environmental supra system. To all parties in this context, a rigorous strategic analysis of market demand, competitor's strength and ambitions, Porter four forces combined with risk assessment may be more complex but it certainly provides better insight and more importantly facilitates timely and appropriate reactions when black swan occurs.

\section{References}

[1] Brigham, E. \& Houston, J. (2013). Fundamental of financial Management, $13^{\text {th }}$ Edition, USA: South Western Cen gage Learning.

[2] CSP (2012). Federal Republic of Nigeria, Country Strategy Paper 2012 - 2016, Regional Department West 1, December, African Development Bank \& African Development Fund.

[3] Eaton, D. (2013). Risk and Financial Management Module Lecture Material, Taught Masters Programme, University of Salford, 2012/2013 session.

[4] NBS (2012). National Bureau of Statistics National Economy Forecast, Last Quarter, Abuja.

[5] Oluwakiyesi, T. (2011). Construction Industry Report: a Haven of Opportunities, Abuja: Vetiva Capital Management Ltd.

[6] Tosin, M.A. (2012). Harnessing Our Diversity and Strength for National Development, First Prize Winning Essay, 2012 Yakubu Gowon Foundation Essay Competition.

[7] Porter, M.E. (1991). Towards a Dynamic Theory of Strategy, Strategic Management Journal, 12: 95-117.

[8] Schwab, K. (2012). The Global Competitiveness Report 2012 - 2013 Full Data Edition, World Economic Forum, Geneva.

[9] Taleb, N. H. (2010). The Black Swan, Impact of the Highly Improbable, London: Penguin Group Ltd.

[10] Weiner, S. B. (2008). How to live in a World of Black Swans: Nassim Nicholas Taleb's Take on the Financial Crisis, Advisor Perspectives Inc. 